\title{
CONTRIBUIÇÃO À GEOLOGIA DE SUBSUPERFÍCIE E À PALEONTOLOGIA DO GRUPO TUBARÃO NO ESTADO DE SÃO PAULO
}

\author{
Geólogo SÉRGIO MEZZALIRA - Pesquisador Científico
}

\section{RESUMO}

A abertura de poços para captação de água subterrânea, em diversas localidades do Estado de São Paulo, pelo Instituto Geológico (ex-Instituto Geográfico e Geológico) tem-nos permitido obter não só novos dados litoestratigráficos como paleontológicos que permitem ampliar o conhecimento e o comportamento geopaleontológico do Grupo Tubarão no Estado de São Paulo.

São descritos perfis geológicos de poços abertos em: Sarapuí, em número de dois com profundidades de $138 \mathrm{~m}$ e $130 \mathrm{~m}$; Itu, em número de 4 com $81 \mathrm{~m}, 87 \mathrm{~m}$, $100 \mathrm{~m}$, e $134 \mathrm{~m}$ de profundidades e Salto de Pirapora, com $119 \mathrm{~m}$.

Nos poços perfurados nas três localidades inicialmente mencionadas, só foram cortados sedimentos do Grupo Tubarão, atingindo nas duas últimas o Embasamento representado aqui por termos do Grupo São Roque (filito - quartzítico, calcífero compacto).

Nos poços de Sarapuí, foram encontrados: no n. ${ }^{\circ} 1$, Restos e fragmentos de vegetais (hastes principalmente) carbonizados e não carbonizados e o megásporo Lagenoisporites (Trileites) brasiliensis (Dijkstra, 1955); no n. 2, também, inúmeros restos e fragmentos de vegetais carbonizados e não carbonizados e o vegetal ?Plumsteadiella sp.

\section{ABSTRACT}

The well drilling to get ground water supply in the State of São Paulo, Brazil, through the cooperation of the Geological Institute (Ex-Instituto Geográfico e Geológico) led not only to new stratigraphic data but also to paleontological observations which enlarged broadly our knowledgment about the geology concerning Tubarão Group on the State of São Paulo.

In this paper geological profiles are assigned to Sarapuí wells (two, depth: $138 \mathrm{~m}$ and $130 \mathrm{~m}$ ), Itu (four, depths: $81 \mathrm{~m}, 87 \mathrm{~m}, 100 \mathrm{~m}$ and $134 \mathrm{~m}$ ), Salto de Pirapora (one, depth: $119 \mathrm{~m}$ ). In the three former localities the wells cut only Tubarão Groups sediments, and the two latter have reached the São Roque Embasement rocks.

In the Sarapuí wells were found the following fossils: in the $n .^{\circ} 1$ plant remnants and fragments (mainly stems many thoroughly carbonzied and few not yet been and besides that we found Lagenoisporistes (Trileites) brasiliensis (Dijkstra 1955) Trindade, megaspores. In the $n .^{\circ} 2$ there are several carbonized (party and thoroughly) plant fragments and remnants asd ?Plumsteadiella sp.

\section{INTRODUÇÃO}

Entre os diversos trabalhos de pesquisa do Instituto Geológico (antigo Instituto Geográfico e Geológico), da Cocrdenadoria da Pesquisa de Recursos Naturais, da Secretaria da Agricultura e Abastecimento do Estado de São Paulo, inclui-se a de estratigrafia (litológica e biológica) de superfície e subsuperfície nas diversas formações sedimentares ocorrentes no Estado.

A pesquisa de subsuperfície é feita nos testemunhos obtidos nas perfurações de poços profundos, executados pelo Instituto Geológico, para captação de água subter. 
rânea. O objetivo do presente trabalho é divulgar esses dados estratigráficos (litoló. gicos e biológicos), obtidos em sondagens executadas em Sarapuí, I $\mathbf{t}^{\mathfrak{r} l,}$, Salto de Pirapora, todas localidades do Estado de São Paulo, contribuindo para maior conhecimento espacial e subsuperficial do Grupo Tubarão.

As perfurações realizadas em Itu e Salto de Pirapora, vieram confirmar observações anteriores do A., na região, isto é, da presença de termos litológicos do Grupo São Roque subjacentes aos sedimentos do Grupo Tubarão e não do granito ou gnaisse (MEZZALIRA, 1969).

\section{SITUAÇÃO GEOGRÁFICA}

A cidade de Itu, SP, está a cerca de $100 \mathrm{~km}$ a WNW de São Paulo, e é servida pela FEPASA (ramal de Itu) e por linhas de ônibus intermunicipais. Salto de Pirapora, SP, encontra-se a cerca de $20 \mathrm{~km}$ ao S. de Sorocaba e esta, por sua vez, dista de São Paulo cerca de $100 \mathrm{~km}$. É também servida pela FEPASA. (Ferrovias Paulista S.A.).

Sarapuí, SP, está a $150 \mathrm{~km}$ a WSW da Capital e é servida pela rodovia Raposo Tavares, da qual dista cerca de $10 \mathrm{~km}$ dessa estrada.

As cidades encontram-se na área dos sedimentos paleozóicos, constituindo uma das unidades com características geomorfológicas e geográficas próprias e que foi denominada como Depressão Periférica por Moraes Rêgo em 1932 e subdividida em três zonas por Deffontaines em 1935. (IN ALMEIDA, 1964 p. 228). Assim, Salto de Pirapcra e Sarapuí situam-se na zona do Paranapanema e Itu, na Zona do médio Tietê.

\section{GEOLOGIA DE SUBSUPERFICIE}

\section{(Litoestratigrafia)}

A divulgação dos dados obtidos nas novas perfurações, constitui uma das finalidades deste trabalho.

Poços Profundos em Itu, SP: A cidade de Itu como as de Sorocaba, Salto de Pirapora, Campinas, etc., encontra-se próxima do contato sedimentos carboníferos com o Pré-Cambriano. Geomorfologicamente, situa-se na chamada Depressão Periférica.
Os sedimentos mais comuns ocorrentes em torno da cidade e das novas perfurações são os arenitos, siltitos, ritmitos e diamictitos, referentes ao Grupo Tubarão (englobadas aqui as Formações Itararé e Tatuí). A espessura desses sedimentos nos arredores é muito variável entre $0 \mathrm{~m}$ e $180 \mathrm{~m}$, devido à irregularidade do relevo do embasamento.

Baseado nos dados de poços profundos existentes na região (MEZZALIRA, 1969, p. 89) verifica-se que na parte sul da cidade (saída para Sorocaba e rodovia Castelo Branco) a espessura dos sedimentos varia entre $65 \mathrm{~m}$ e $90 \mathrm{~m}$; para sudoeste, atinge $75 \mathrm{~m}$; mais para oeste, na estrada do Jacu, alcança $100 \mathrm{~m}$ e na estrada para Porto Feliz, chega a $180 \mathrm{~m}$. Na parte norte e leste, os sedimentos se adelgaçam e surgem os granitos na rodovia para Salto, e gnaisЂes, aplitos e granitos (na rodovia para São Paulo).

Os granitos comuns, na região, são de granulação grosseira, apresentam fenocristais de microclínio róseo, quartzo e rara biotita e são conhecidos como Granito de Itu.

Nos arredores da Granja Santa Rosa, vila São José, situada a $2 \mathrm{~km}$ SSW de Itu, estão presentes os siltitos, ritmitos e diamictitos referentes ao Grupo Tubarão e, na Estância Ituana, bairro Guatapendava a $6 \mathrm{~km}$ a SSW da cidade, predominam os siltitos argilosos de cores cinza e amarelo. com pequena ocorrência de diamictito nas margens e leito do ribeirãc Itaim que corta a área da Estância. A cerca de $3 \mathrm{~km}$ desse ponto situam-se as pedreiras de exploração dos ritmitos (varvitos) contendo os rastos fósseis de crustáceos.

As características dos poços são as seguintes:

Poço Vila Santa Teresinha; Itu, SP:

Altitude - $535 \mathrm{~m}$

Profundidade total $-87 \mathrm{~m}$

Perfil litoestratigráfico - segundo

o Eng. S. M. Chaves 


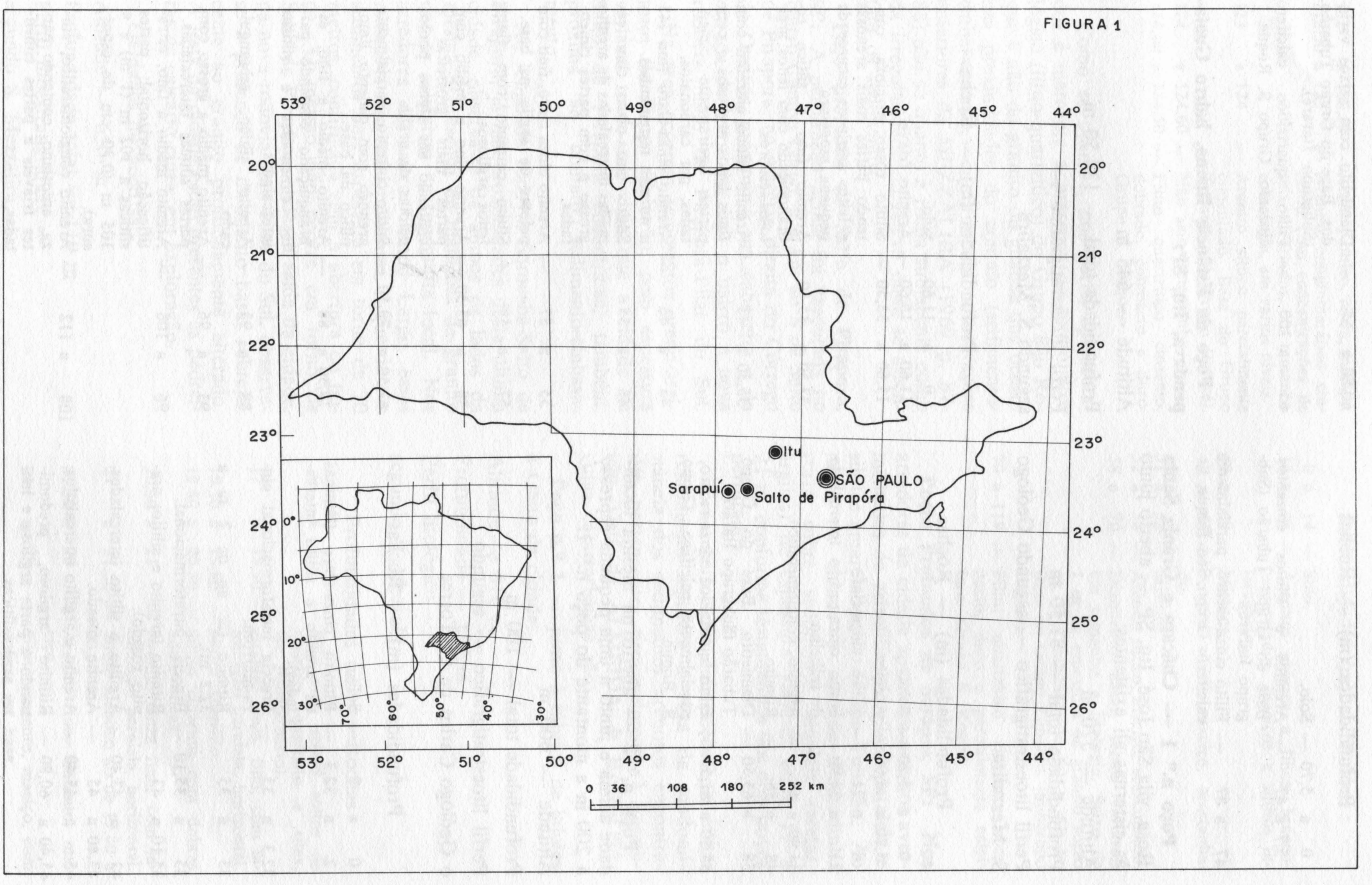




\author{
Profundidades (m) - Rochas \\ 0 a 5,70 - Solo. \\ 5,7 a 47 - Arenitos e siltitos cinzentos \\ Base do Grupo Tubarão (Sub- \\ grupo Itararé). \\ 47 a 87 - Filito cinza-escuro, parcialmente \\ calcífero. Grupo São Roque.
}

Poço n. 1 - Chácara e Granja Santa Rosa, vila São José, Itu, SP - aberto junto às cisternas ali existentes:

Altitude $-570 \mathrm{~m}$

Profundidade total $-81,50 \mathrm{~m}$

Perfil litoestratigráfico — segundo Geólogo S. Mezzalira.

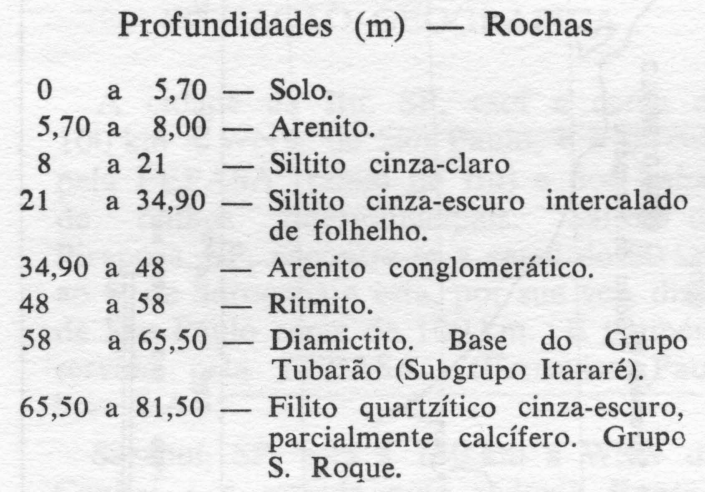

Poço n.o 2 - aberto na mesma localidade acima e junto a uma pequena represa, a $200 \mathrm{~m}$ a montante do poço $\mathrm{n} .^{\circ} 1$ :

Altitude $-600 \mathrm{~m}$

Profundidade total $-100 \mathrm{~m}$

Perfil litoestratigráfico - segundo

o Geólogo Carlos de C. Torres$$
\text { Profundidades (m) - Rochas }
$$$$
0 \text { a } 2 \text { - Solo. }
$$$$
2 \text { a 32,3 - Ritmito cinza-claro (lâminas }
$$
de arenito e siltito intercaladas).

32,3 a 33 - Breccia intraformacional cinza-marrom.

33 a 35 - Ritmito (= ao de $2 \mathrm{~m}$ a $32,3 \mathrm{~m})$.

35 a 35,10 - Breccia intraformacional.

35,10 a 43 - Ritmito (arenito e siltito; arenito rosado).

43 a 43,40 - Argilito e siltito intercalados.

43,40 a 45 - Arenito rosado.

45 a 45,40 - Arenito e argilito intercalados.

45,40 a 60,80 - Ritmito argiloso, predominando a parte argilosa e lentes areno-sílticas.
}

\begin{abstract}
60,80 a 65 - Diamictito com seixos variados. Base do Grupo Tubarão. (Subgrupo Itararé).

65 a 100 - Filito quartzítico calcífero cinzento. Grupo S. Roque.
\end{abstract}

Poço da Estância Ituana, bairro Guatapendava, Itu, SP:

Altitude - $645 \mathrm{~m}$

Profundidade total $-134,50 \mathrm{~m}$

Perfil litoestratigráfico -

segundo S. Mezzalira

$$
\text { Profundidades (m) - Rochas }
$$

$$
\begin{aligned}
& 0 \text { a } 11,60 \text { - Solo. } \\
& 11,60 \text { a 15,60 - Arenito friável. } \\
& 15,60 \text { a } 33,50 \text { - Siltito róseo e cinza, con- } \\
& \text { tendo partes mais arenosas } \\
& \text { e leitos argilosos escuros de } \\
& \text { pequena espessura. } \\
& 33,50 \text { a } 35,50 \text { - Arenito fino a síltico es- }
\end{aligned}
$$


112 a 118,50 - Arenito síltico, cinza, maciço. 118,50 a 123 - Arenito conglomerático cinzento com concentrações de seixos variados, em tamanho e litologia, em vários níveis.

123 a 124 - Arenito síltico parcialmente cimentado. Base do Grupo Tubarão. (Subgrupo Itararé).

124 a 124,60 - Não saiu testemunho.

124,60 a 134,50 - Filito quartzítico cinzento, dobrado, compacto e duro. Grupo S. Roque.

Como se observa, nos perfis apresentados é marcante a presença do termo litológico (filito-quartzítico) do Grupo São Roque e não do granito ou gnaisse que ocorre nas proximidades do contato (sedimentoembasamento), confirmando observações anteriores de MEZZALIRA (1969 p. 8788) não só quanto à rocha subjacente como da irregularidade do relevo onde se assentam os sedimentos.

Poço profundo de Salto de Pirapora, SP: A perfuração acima foi executada no bairro Campo Largo, a $4 \mathrm{~km}$ ao $\mathrm{S}$ de Salto de Pirapora, na margem direita do Córrego do Ourives, próximo à sua cabeceira e da estrada de terra que liga o bairro à nova rodovia Salto de Pirapora-Pilar do Sul.

$\mathrm{Na}$ área ocorrem sedimentos areno-argilosos do Grupo Tubarão, com espessura variável tendo em vista que a cidade de Salto de Pirapora encontra-se, também, próxima ao contato sedimento-embasamento.

Ao longo da rodovia Sorocaba-Salto de Pirapora, já nas proximidades desta última cidade, observa-se de ambos os lados da mesma a presença de matacões de granito que se salientam na topografia local. Nos arredores do bairro Campo Largo, esses matacões não estão presentes, o que dá aos sedimentos uma espessura em torno de 70 metros, confirmada com a abertura do poço. O mesmo não ocorre em torno de Salto de Pirapora, onde na saída da cidade, na nova rodovia para Pilar do Sul, observase a presença de diamictito basal sobrejacente ao granito profundamente alterado. A leste da cidade estão presentes as pedreiras de calcário cinza, em exploração.

Os dados do poço são:

Altitude $-650 \mathrm{~m}$

Profundidade total $-119 \mathrm{~m}$

Perfil litoestratigráfico -

segundo S. Mezzalira

\section{Profundidades $(\mathrm{m})$ - Rochas}

0 a 14 - Solo.

14 a 48 - Arenitos grossos a finos, branco-amarelados, maciços e síltitos intercalados.

48 a 49 - Mistitos.

49 a 51 - Arenito síltico, maciço, acastanhado.

51 a 52 - Mistitos.

52 a 58 - Arenito síltico, maciço, acastanhado.

58 a 70 - Diamictito basal, seixos variáveis em tamanho e litologia. Seixo de $1 \mathrm{~m}$ de espessura de granito róseo na profundidade de 60 a $61 \mathrm{~m}$. Base do Grupo Tubarão. (Subgrupo Itararé).

70 a 119 - Filito quartzítico cinzento compacto, duro e parcialmente calcífero. Grupo S. Roque.

Poços Profundos de Sarapuí, SP: Nos arredores da cidade aparecem arenitos avermelhados de estratificação plano-paralela e siltitos amarelados, do Grupo Tubarão. Ao norte da cidade o ribeirão Fazendinha corre sobre sedimentos aluviais (areias, argilas) de espessura variável entre 17 a $21 \mathrm{~m}$, conforme testemunhos dos dois poços perfurados.

Foram perfurados dois poços com ótimo rendimento aquíf́ero à vista da predominância dos sedimentos arenosos encontrados, pertencentes, provavelmente, à Formação Tietê de ALMEIDA \& BARBOSA, cujas características são:

Poço n.* 1 - junto à fábrica de lajotas a Oeste da cidade:

Altitude $-610 \mathrm{~m}$

Profundidade $-138 \mathrm{~m}$

Perfil litológico -

segundo S. Mezzalira

Profundidades $(\mathrm{m})$ - Rochas

0 a 17 - Solo com seixos soltos de quartzo, quartzito e sílex, etc. (Quaternário).

17 a 19,30 - Arenito cinza, fino, com laminação paralela, horizontal.

19,30 a 19,80 - Siltito cinzento.

19,80 a 20,50 - Siltito cinzento com dobras adiastróficas.

20,50 a 21 - Arenito cinza fino, com laminação paralela, horizontal.

21 a 21,50 - Siltito idêntico ao de 19,80 a $20,50 \mathrm{~m}$.

21,50 a 23 - Arenito fino, cinzento, ma. ciço.

23 a 24 - Siltito cinzento, maciço, com dobras na base. 


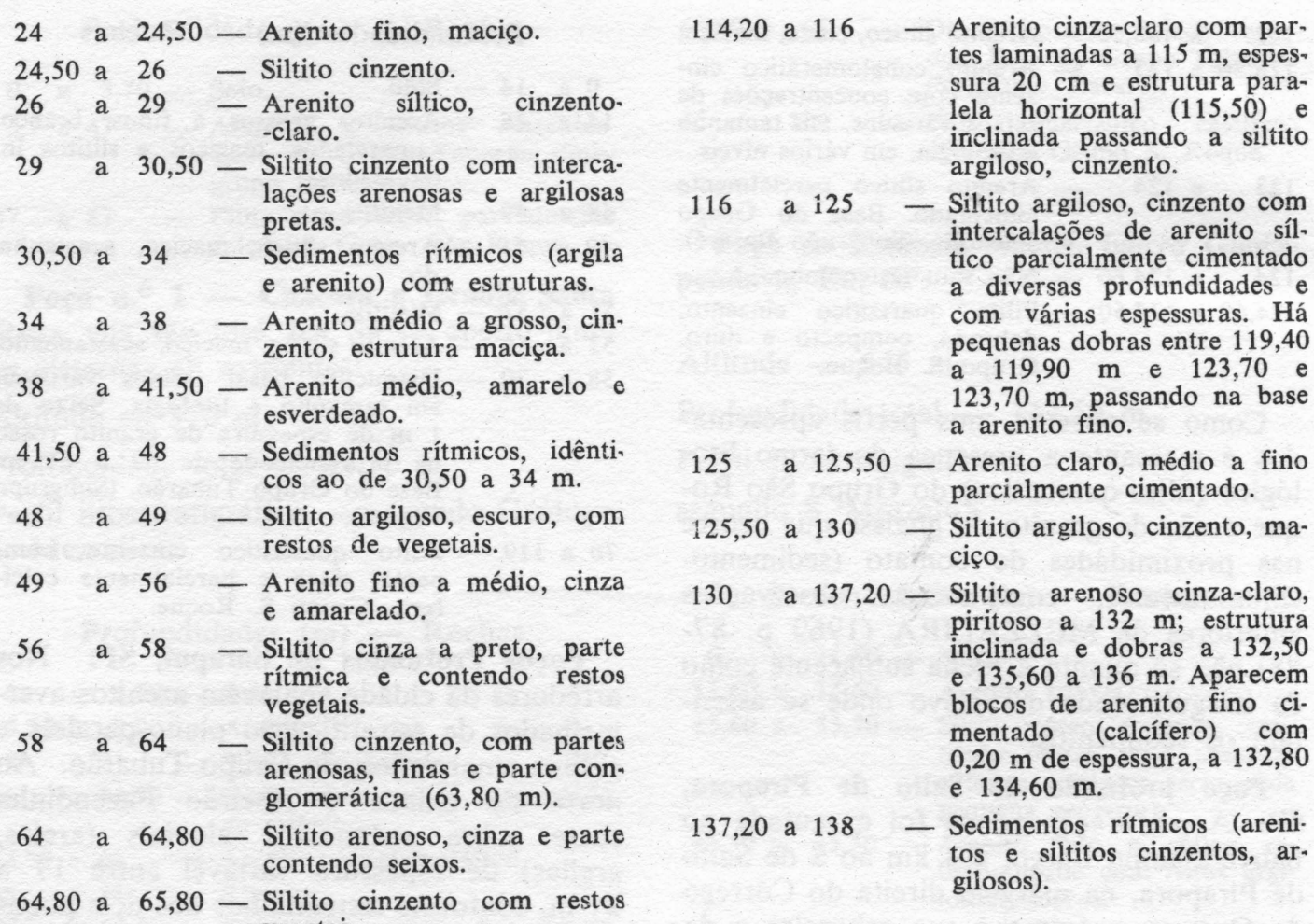
rítmica e contendo restos vegetais. 58 a 64 - $\begin{aligned} & \text { Siltito cinzento, com partes } \\ & \text { arenosas, finas e parte con- }\end{aligned}$ glomerática $(63,80 \mathrm{~m})$.

64 a 64,80 - Siltito arenoso, cinza e parte contendo seixos.

64,80 a 65,80 - Siltito cinzento com restos

114,20 a 116 - Arenito cinza-claro com par. tes laminadas a $115 \mathrm{~m}$, espessura $20 \mathrm{~cm}$ e estrutura paralela horizontal $(115,50)$ e inclinada passando a siltito argiloso, cinzento.

116 a 125 - Siltito argiloso, cinzento com intercalações de arenito síltico parcialmente cimentado a diversas profundidades e com várias espessuras. Há pequenas dobras entre 119,40 a $119,90 \mathrm{~m}$ e 123,70 e $123,70 \mathrm{~m}$, passando na base a arenito fino.

125 a 125,50 - Arenito claro, médio a fino parcialmente cimentado.

125,50 a 130 - Siltito argiloso, cinzento, maciço.

130 a 137,20 - Siltito arenoso cinza-claro, piritoso a $132 \mathrm{~m}$; estrutura inclinada e dobras a 132,50 e 135,60 a $136 \mathrm{~m}$. Aparecem blocos de arenito fino cimentado (calcífero) com $0,20 \mathrm{~m}$ de espessura, a 132,80 e $134,60 \mathrm{~m}$.

137,20 a 138 - Sedimentos rítmicos (arenitos e siltitos cinzentos, argilosos). vegetais.

65,80 a 67 - Siltito parcialmente arenoso, cinzento.

67 a 70 - Arenito médio a grosso com partes seixosas e com restos vegetais.

70 a 73 - Siltito cinzento com vegetais no topo.

73 a 75 - Sedimentos rítmicos (idênticos aos anteriores).

75 a 79 - Arenitos finos e siltitos cinzentos.

79 a 80 - Siltito argiloso, escuro, com restos de vegetais.

80 a 86 - Arenitos finos e siltitos cinzentos, com finas camadas argilosas intercaladas.

86 a 87 - Siltito preto com vegetais fósseis.

87 a 88 - Arenito médio, cinzento, maciço.

88 a 104 - Siltito argiloso cinzento- escuro, com intercalações de manchas claras.

104 a 107,50 - Siltito cinzento-escuro, fratura concoidal.

107,50 a 114 - Arenito médio a fino, cinza-claro, maciço, com finas camadas argilosas escuras, de 110,70 a $110,90 \mathrm{~m}$. O arenito tem partes friáveis e laminação paralela inclinada $(112,20$ a $112,60 \mathrm{~m})$.

114 a 114,20 - Siltito argiloso, escuro, com restos de vegetais carbonizados.
Poço n.. $2-a \pm 200 \mathrm{~m}$ a jusante do P. n. ${ }^{\circ} 1$, no fím da rua Leôncio Pinheiro:

Altitude - $605 \mathrm{~m}$

Profundidade total $-130 \mathrm{~m}$

Perfil litológico - segundo S. Mezzalira

$$
\text { Profundidades (m) - Rochas }
$$

0 a 21 - Solo e areia com seixos de sílex (Quaternário).

21 a 29,80 - Siltito cinzento-escuro, fratura concoidal, contendo $0,20 \mathrm{~m}(25,20$ a 25,40$)$ de seixos de pequeno diâmetro (argilito, quartzo, granito, etc.); intercalações arenosas, média, cinza a partir de $28 \mathrm{~m}$, passando a siltito are. noso cinza-claro, seixoso, na base.

29,80 a 37,80 - Não saiu testemunho (arenito cinza friável).

37,80 a 38 - Arenito argiloso, avermelhado, micáceo.

38 a 38,50 - Folhelho carbonoso com

38,50 a 45 - Arenito síltico esbranquiçado e cinza, maciço, micáceo, com laminação paralela ho. rizontal $(43,50$ a $45 \mathrm{~m})$.

45 a 46 - Siltito preto passando na base a amarelado, com restos de vegetais fósseis. restos de vegetais. 


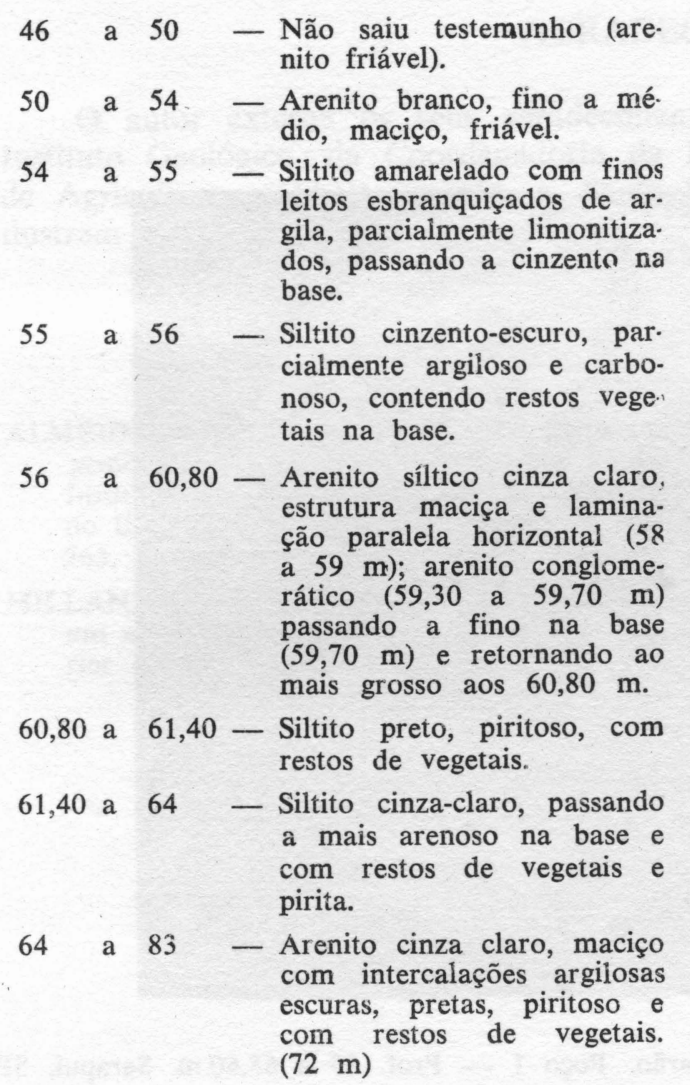

83 a 83,20 - Siltito preto piritoso e carbonoso.

83,20 a 98 - Arenito síltico cinzento, claro e escuro, maciço, falsa rit. micidade.

98 a 104,20 - Siltito cinzento, argiloso, fratura concoidal.

104,20 a 112 - Arenito, cinza escuro, fino a média, maciço, com algumas intercalações de leitos argilosos escuros. Laminação paralela horizontal na base.

112 a 119 - Siltito cinzento com intercalações de leitos arenosos cinza escuro. $\mathrm{O}$ siltito tem fratura concoidal e com microfalhas (112 m) e, o arenito, laminação paralela horizontal devido à presença de minerais máficos nas camadas escuras.

119 a 130 - Arenito cinza claro, cimentado, fino, laminação paralela-horizontal no topo, passando a maciça até $122 \mathrm{~m}$; de 122 a $124 \mathrm{~m}$ finos leitos argilosos escuros intercalados; entre 127 e $128 \mathrm{~m}$ estrutura inclinada; de 124 a $127 \mathrm{~m}$ laminação paralela horizontal e maciça, tornando-se de cor cinza mais escura de 128 a $130 \mathrm{~m}$.
As rochas dos poços 01 e 02 , acima, são referíveis ao Grupo Tubarão (subgrupo Itararé).

\section{CONTEUDO PALEONTOLÓGICO}

Somente nos poços de Sarapuí, SP, foram encontrados os seguintes fósseis:

\section{Poço 1 - Sarapuí, SP}

Fósseis do Grupo Tubarão Profundidade (m)

a) Megásporos

$$
\begin{aligned}
& \text { - } 1 \text { Lagenoisporites } \\
& \text { (Trileites) brasiliensis } \\
& \text { (Dijkstra 1955) (três } \\
& \text { níveis) }
\end{aligned}
$$

43,$50 ; 47,50 ; 48,30$

b) Fragmentos de vegetais carbonizados, constituindo camada de carvão. Presença de pirita.

48,90

c) Fragmentos de vegetais carbonizados e não carbonizados (hastes principalmente) (Foto n. ${ }^{\circ}$ 1) 48,$80 ; 65$ a 65,60 ; 86,$50 ; 114$

\section{Poço 2 - Sarapuí, SP}

\section{Fósseis do Grupo Tubarão}

Profundidade (m)

a) Fragmentos de vegetais carbonizados e piritosos (folhelho carbonoso - $\pm 1 \mathrm{~m}$ de espessura)

b) Fragmentos de vegetais, principalmente hastes, em arenito amarelado

c) Fragmentos de vegetais (hastes) carbonizados

d) ? Plumsteadiella sp. (Foto n. ${ }^{\circ}$ 02)

Noticia-se aqui, pela primeira vez no Estado de São Paulo, da ocorrência do gênero Plumsteadiella sp. em sedimentos do Grupo Tubarão. Constitui a segunda ocorrência para o Brasil, devendo-se a primeira referência a MILLAN (1969) que descreveu Plumsteadiella apedicellata Millan encontrada no Estado de Santa Catarina em sedimentos do subgrupo Guatá, Formação Rio Bonito, Grupo Tubarão.

O exemplar paulista, ora noticiado, pertence, provavelmente, ao subgrupo Itararé, Grupo Tubarão. 
Rev. IG, São Paulo, 1(2):39-47, jul./ dez. 1980

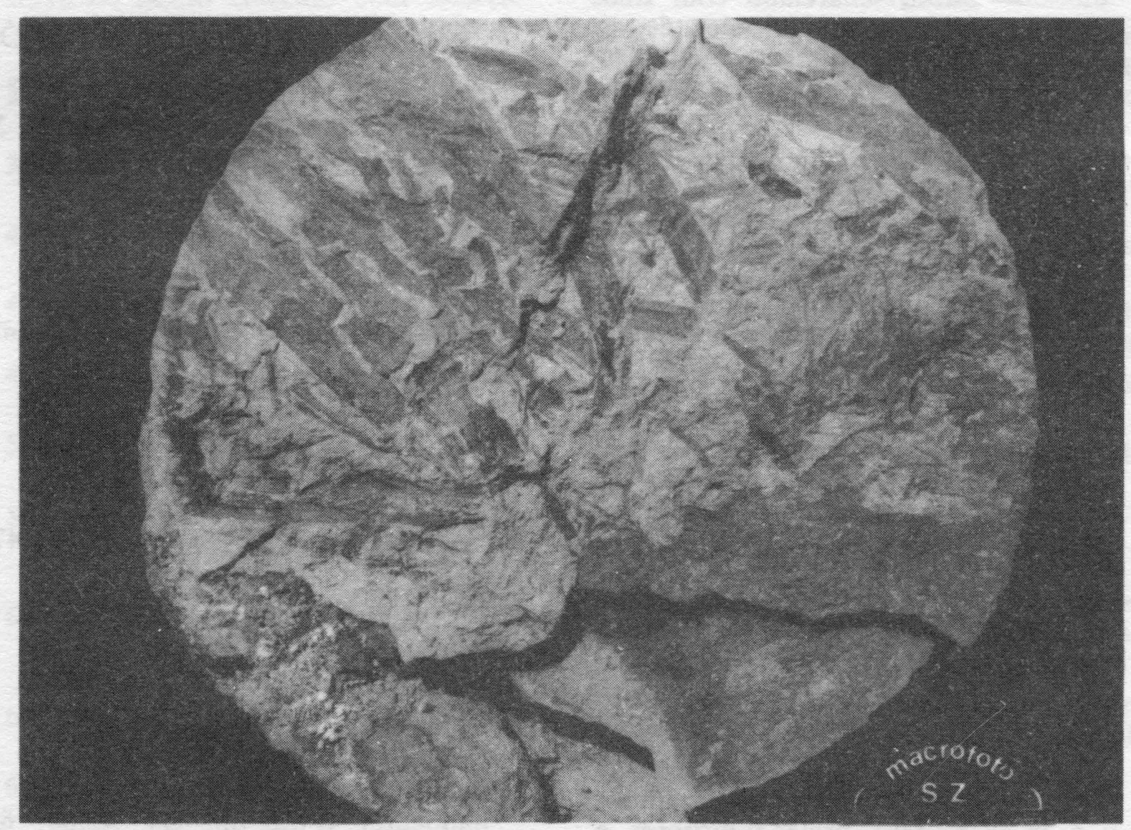

FOTO N. 01 - Restos de vegetais. Grupo Tubarão. Poço 1 - Prof. 65 a 65,60 m. Sarapuí, SP.

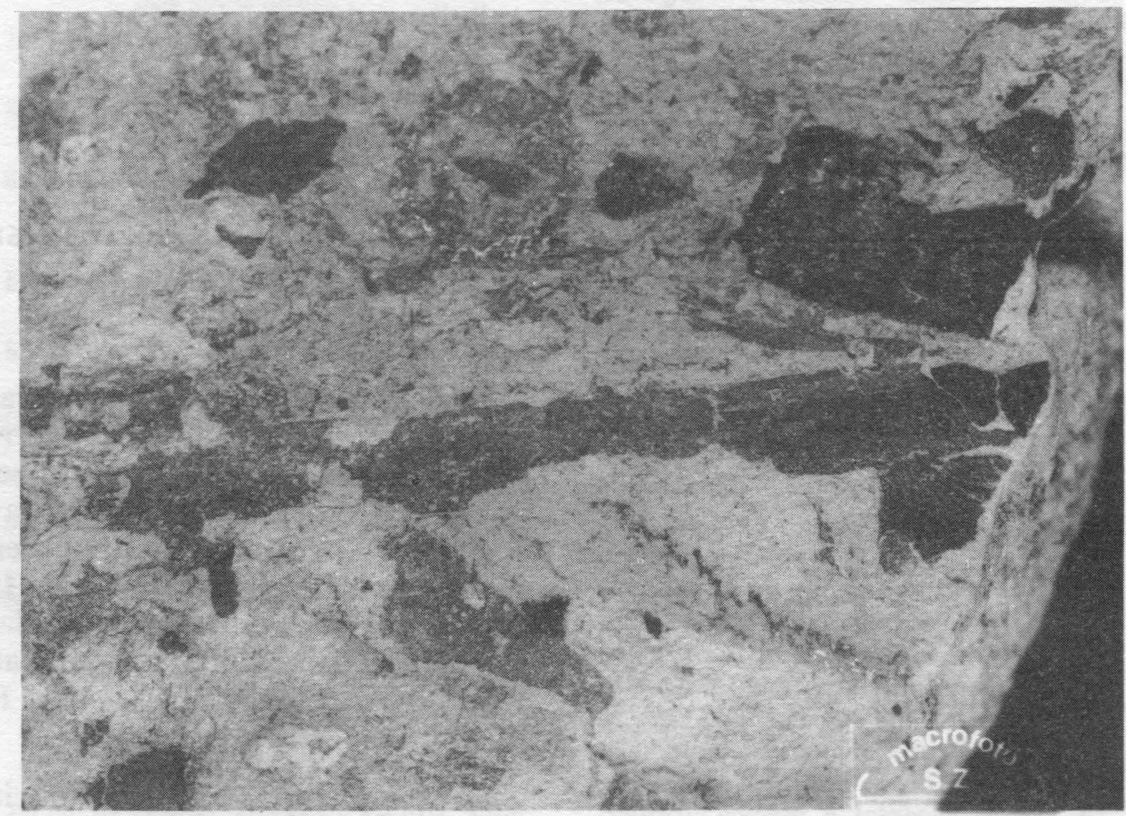

- FOTO N. ${ }^{\circ} 02$ - ? Plumsteadiella sp. Poço n. ${ }^{\circ} 2$ - Prof. 62 m. Grupo Tubarão. Sarapuí, SP. 
Rev. IG, São Paulo, 1(2):39-47, jul./dez. 1980

\section{AGRADECIMENTOS}

O autor externa os seus agradecimentos aos Srs. Pedro Pacchiella Comério, do Instituto Geológico, da Coordenadoria da Pesquisa de Recursos Naturais da Secretaria de Agricultura e Abastecimento, e, Saulo Succhello pela execução das fotografias que ilustram este trabalho.

\section{BIBLIOGRAFIA}

ALMEIDA, F.F.M. de - 1964 - Fundamentos geológicos do relevo paulista. In: São Paulo. Instituto Geográfico e Geológico. Geologia do Estado de São Paulo. São Paulo. p. 167263. (Boletim, n. ${ }^{\circ} 41$ )

MILLAN, J. H. - 1969 - Sobre Plumsteadiella um novo vegetal comum ao Gondwana inferior do Brasil e da África do Sul. Rio de
Janeiro, Museu Nacional. 10p. il. (Boletim. Nova Série, Geologia, 34)

MEZZALIRA, S. - 1969 - Geologia de sub-superfície em Itu, SP: ocorrência de Rocha Moutonée nos testemunhos de sondagem. An. Acad. Bras. Ci., Rio de Janeiro, 41(1):83-89.

TRINDADE, Nicea M. - 1969 - Megásporos permianos da formação Corumbataí, Estado de São Paulo. An. Acad. Bras. Ci., Rio de Janeiro, 41(3):415-420. 